Session \#2793

\title{
Linking Entering Students Survey Data and Freshman Performance to Improve Advisement Services
}

\author{
Raymond Calluori, Ph.D., Angelo Perna, Ph.D., Zola, Martha, Ph.D. and Briller, Vladimir, \\ Ph.D. \\ New Jersey Institute of Technology
}

\begin{abstract}
The paper seeks to examine the relationship between students' goals (i.e. motivations) on the Entering Student Survey administered to the incoming Freshman class, level of commitment toward finishing a degree and Freshman academic performance (i.e., learning). Its purpose is to assist advisement services to Engineering students at a large urban public university.
\end{abstract}

As part of the Entering students survey, students are asked to rate the importance of goals in their decision to enroll. Student motivational theories maintain that there are two types of learning motivation: (1) intrinsic and (2) extrinsic. Intrinsically motivated learning is learning "for its own sake, for the enjoyment it provides, the learning it permits, or the feelings of accomplishment it evokes" (Lepper, 1998). Extrinsically motivated learning is learning "in order to obtain some reward or avoid some punishment external to the activity itself" (Lepper, 1998). This study deals with intrinsic and extrinsic motivators.

Freshman cumulative grade point averages for $1^{\text {st }}$ and $2^{\text {nd }}$ semester were used as the measures of academic performance. The data were collected for 456 Engineering students who participated in the Entering Student Surveys in Fall of 1999 and 2000. Since the Entering Students for the last three years have consistently ranked career oriented goals high, the research suggests that the extrinsically motivated goals are more likely related to a high level of commitment and successful Freshman academic performance.

The implications of these findings will be relevant in the faculty advisement of students. The students will be better served in matching their goals and course selection, which will ultimately lead to improved learning.

\section{Introduction}

The paper is a part of a larger study on retention and graduation (Zola, 2000). Its purpose is to assist advisement services to Engineering students at a large urban public university. The paper examines the relationship between students' goals (i.e. motivations) on the Entering Student Survey that has been administered to the incoming Freshman class, level of commitment to graduate and Freshman academic performance (i.e., learning). 
In 1999, an Entering student survey of first-time full-time freshmen (FTFTF) was designed and implemented. It has been given on an annual basis for the last three years. The main purpose of the survey was to describe the goals and desired outcomes of FTFTF. As part of the Entering students survey, student were asked to rate the importance of goals in their decision to enroll as well as their commitment to graduate.

Motivation is an internal state or condition that activates and directs goal-oriented behavior (Kleinginna and Kleinginna, 1981). Research has demonstrated that motivation is a key component of learning (Stipek, 1988). Student motivational theories maintain that there are two types of learning motivation: (1) intrinsic and (2) extrinsic. Intrinsically motivated learning is learning "for its own sake, for the enjoyment it provides, the learning it permits, or the feelings of accomplishment it evokes" (Lepper, 1988). Extrinsically motivated learning is learning "in order to obtain some reward or avoid some punishment external to the activity itself" (Lepper, 1988). In general, instrinsic motivativors are championed in the literature since intrinsic motivated learning has been linked to high-quality learning and adjustment (Benware and Deci, 1984) However, it also has been argued that extrinsic rewards enhance motivation and performance (Cameron, 2001). This study attempts to explore the intrinsic and extrinsic motivators of freshman engineering students via the Entering students survey.

Freshman cumulative grade point averages for $1^{\text {st }}$ and $2^{\text {nd }}$ semester were used as the measures of academic performance. The data were collected for 456 engineering students who participated in the Entering Student Surveys in Fall of 1999 and 2000. Since the findings of the Entering Students for the last three years have consistently ranked career oriented goals high, it will be argued that will that the extrinsically motivated goals among Freshman engineering students are more likely related to a high level of commitment and successful Freshman academic performance.

Methodology

a) Design -

Correlations analysis (Pearson correlation) of the twelve goals correlating with cumulative grade point average (cumgpa) (dependent variable) and commitment (dependent variable) for a single cohort over time, using survey responses and performance data as independent variables.

Students were surveyed about their goals and commitment at the start of their freshman semester. Academic performance (i.e., cumgpa) for the end of the $1^{\text {st }}$ (Freshman fall) semester and the $2^{\text {nd }}$ (Freshman spring) semester were retrieved from the student system (SIS) and merged to cases in the study file.

b) Sample -

The sample of 456 includes FTFTF students who were freshmen in the fall $1999 \& 2000$ semester and enrolled in the college of engineering. Only FTFTF students who completed the Enrolling Student Survey and included their social security numbers on the 
survey form were included in this study. The majority of the respondents were male and first-generation college students.

c) Instrument -

The survey instrument was an op-scan, paper and pencil form that included 65 items. This study concentrated only on responses to the twelve goal items and the level of commitment question. Students were asked how committed they were to finishing their degree at the university. Their responses were rated from a scale of 1 to 5. The potential responses were (1) somewhat committed, (2) moderately committed, (3) strongly committed, (4) very strongly committed, and (5) and extremely strongly committed.

d) Procedures -

During the first two weeks of their freshman semester (1999/2000), students completed an enrolling student survey in freshman seminar courses (which is a course required for all FTFTF). The forms were collected by freshmen seminar faculty and returned to the Office of Institutional Research and Planning. Forms were op-scanned and converted to a SAS database. The twelve goals were reviewed and characterized as extrinsic or intrinsic by the authors. See Chart 1 below:

\section{Chart 1: Entering Students Goals}

Extrinsic

Obtain a degree.

Prepare for a career.

Obtains skills that will be useful on a job.

Meet the academic requirement for graduate school.

Improve ability to make money.

\section{Instrinsic}

Discover vocational interest.

Increase an awareness of different philosophies, cultures \& way of life.

Learn how to participate effectively as a citizen in the community.

Develop an understanding and appreciation of science/ technology.

Improve self-image.

Simply learn.

Improve personal professional status. 
e) Analysis -

The following steps were taken to analyze the data: All twelve goal items were correlated (Pearson correlation) with the commitment item and cumulative grade point averages for the $1^{\text {st }}$ Freshman semester and the $2^{\text {nd }}$ Freshman semester of the student's freshman year. Items that are significantly correlated are summarized and presented.

Results

In terms of commitment to graduate, all twelve goal items were correlated. Eight of the goal items (Obtain a degree, Prepare for a career, Attain skills that will be useful on a job, Meet academic requirements for graduate school, Improve ability to make more money, Develop an understanding and appreciation of science/technology, Simply learn, Improve professional status) correlated with a significance of $<.0001$. The majority of these items are extrinsically motivated goals. See Table 1.

The remaining four goals (Learn how to participate effectively as a citizen in the community, Increase cultural awareness of different philosophies, cultures and ways of life, Discover vocational interest, Improve self-image), which are correlated, to a lesser extent with commitment were all intrinsic goals. 


\begin{tabular}{|c|c|c|}
\hline Variable & $\begin{array}{c}\text { Pearsoncorrelation } \\
\text { cofficient }\end{array}$ & $\operatorname{sign} .<.05$ \\
\hline \multicolumn{3}{|l|}{ Extrinsic } \\
\hline Obtain a degree. & .36 & $<.0001$ \\
\hline Prepare for a career. & .34 & $<.0001$ \\
\hline $\begin{array}{l}\text { Obtain skills that will be } \\
\text { useful on a job. }\end{array}$ & .27 & $<.0001$ \\
\hline $\begin{array}{l}\text { Meet the academic } \\
\text { requirement forgraduate } \\
\text { school. }\end{array}$ & .32 & $<.0001$ \\
\hline $\begin{array}{l}\text { Improve ability to make } \\
\text { money. }\end{array}$ & .21 & $<.0001$ \\
\hline \multicolumn{3}{|l|}{ Intrinsic } \\
\hline $\begin{array}{l}\text { Develop an understanding } \\
\text { and appreciation of science/ } \\
\text { technology. }\end{array}$ & .18 & $<.0001$ \\
\hline Simply learn. & .19 & $<.0001$ \\
\hline $\begin{array}{l}\text { Improve personal } \\
\text { professional status. }\end{array}$ & .31 & $<.0001$ \\
\hline $\begin{array}{l}\text { Learn how to participate } \\
\text { effectively as a citizen in the } \\
\text { community. }\end{array}$ & .18 & .0001 \\
\hline $\begin{array}{l}\text { Increase an awareness of } \\
\text { different philosophies, } \\
\text { cultures \& way of life. }\end{array}$ & .17 & .0002 \\
\hline Discover vocational interest. & .15 & .0012 \\
\hline Improve self-image. & .12 & .0094 \\
\hline
\end{tabular}

For end of the $1^{\text {st }}$ freshman semester, only two (Meet academic requirement for graduate school, Increase cultural awareness of different philosophies, cultures and ways of life) of the twelve goals correlated with the cumulative grade point average. The former was characterized as extrinsic and latter was characterized intrinsic. See Table 2. 


\section{Table 2: Variables that Correlate with Cumgpa for 1st Freshman Semester}

\section{Pearson correlation cofficient}

Variable

Extrinsic

Meet the academic requirement

sign. $<.05$

for graduate school.

\section{$\underline{\text { Intrinsic }}$}

Increase an awareness of

.0452

different philosophies, cultures

$\&$ way of life.

For end of the $2^{\text {nd }}$ freshman semester, only two (Meet academic requirement for graduate school, Obtain a degree) of the twelve goals correlated with the cumulative grade point average. Both of the goals were characterized as extrinsic. See Table 3.

\section{Table 3: Variables that Correlate with Cumgpa for 2nd Freshman Semester}

\section{Pearson correlation}

Variable

Extrinsic

Obtain a degree.

Meet the academic requirement

for graduate school.

\section{cofficient}

.11

.14 sign. $<.05$

.0316

.0075

Reconfirming our early study (Zola, 2000) cumgpa for the $1^{\text {st }}$ and $2^{\text {nd }}$ Freshman semesters are correlated with commitment to graduate. See Table 4.

\begin{tabular}{|c|c|c|}
\hline Variable & $\begin{array}{c}\text { Pearson correlation } \\
\text { cofficient }\end{array}$ & sign. $<.05$ \\
\hline Cumgpa for 1 st semester & .12 & .0158 \\
\hline Cumgpa for 2 nd semester & .12 & .0258 \\
\hline
\end{tabular}

Implications:

In summary, the findings show a relationship between the twelve goals items and commitment to graduate among Freshman Engineering students. Although extrinsic and intrinsic goals are 
correlated, the former seems to be the preferred learning style. The results for cumgpa and motivators did not show any strong results except for the extrinsic goal of meeting academic requirement for graduate school. Lastly, our previous finding that the cumgpa and commitment to graduate was reaffirmed.

In terms of advising Engineering students, it could be valuable for the advisor to know if a particular student was basically driven by extrinsic or intrinsic motivators. For instance, extrinsically motivated students may benefit more from "hands-on" types of courses whereas intrinsically motivated students may benefit more from "mind-expanding"/theoretical type of courses. Future research could concentrate on development of a template to aid an advisor in profiling a student as intrinsically or extrinsically motivated.

Bibliography

Benware, C. and Deci, E. "Quality of Learning with an Active versus Passive Motivational Set. American Educational Research Journal.” (1984) 21: 755-765.

Cameron, J. "Negative Effects of Reward on Intrinsic Motivation-A Limited Phenomenon: Comment on Deci, Koestner, and Ryan" Review of Educational Research (Spring, 2001) 71, 1: 29-42.

Deci, E., Koestner, R. and Ryan, R. M. "Extrinsic Rewards and Intrinsic Motivation in Education: Reconsidered Once Again.” Review of Educational Research (Spring, 2001) 71, 1: 1-27.

Kleinginna, P., Jr. and Kleinginna, A. "A Categorized List of Motivation Definitions, with Suggestions for a Consensual Definition." Motivation and Emotion, (1981) 5: 263-291.

Lepper, M. "Motivational Considerations in the Study of Instruction." Cognition and Instruction (1998) 5, 4: 289 309.

Stipek, D. (1988). Motivation to Learn: From Theory to Practice. Englewood Cliffs, NJ: Prentice Hall.

Zola, Martha. Risk Factors Associated with the Retention of FTFTF Students in the Freshman to Sophomore Year. Newark: New Jersey Institute of Technology, December 2000.

Bibliographical Information

RAYMOND CALLUORI, Ph.D.: Dr. Calluori received his Ph.D. from Rutgers University in 1984. He is currently a Senior Institutional Research Analyst at the New Jersey Institute of Technology, where he conducts survey research and manages the course evaluation program. He has conducted research and published in the social sciences as well as in survey research technology.

ANGELO J. PERNA, Ph.D.: Dr. Perna received his Ph.D. Degree in Chemical Engineering from the University of Connecticut in 1967. He is currently an Associate Dean of Engineering at New Jersey Institute of Technology. He is the recipient of numerous awards and in June 2001 he became the first recipient of Robert G. Quinn National Award. He is a Fellow in both the American Institute of Chemical Engineers and the ASEE. 
MARTHA ZOLA, Ph.D.: Dr. Zola is the Executive Director of Institutional Research and Planning at the New Jersey Institute of Technology. She has performed research and published on student retention in higher education as well as in other areas relative to issues in higher education. She has taught statistics, research design, and educational research courses.

VLADIMIR BRILLER, Ed.D.: Dr. Briller received Ed.D. from Columbia University in 1995. He worked as an Associate Project Director at Education Development Center International Department in New York and as a Research Project Director at Vera Institute of Justice in New York evaluating various programs in the US and Europe. Currently, he is a Director of the Outcomes Assessment at NJIT. 